\title{
The contribution of miR-122 to the innate immunity by regulating toll-like receptor 4 in hepatoma cells
}

\author{
Liyu Shi ${ }^{1,2+}$, Xiaoqiu Zheng ${ }^{1,2+}$, Yuzhuo Fan ${ }^{1}$, Xiaolan Yang ${ }^{1,2}$, Aimei Li $i^{1,2}$ and Jun Qian ${ }^{1,2^{*}}$
}

\begin{abstract}
Background: Hepatocellular carcinoma (HCC) is a kind of malignancies to impact human health. It has been reported that aberrant toll-like receptor (TLR) signaling may contribute to the development and progression of HCC, especially TLR4. MiR-122, which extensively involved in hepatitis virus infection and the apoptosis of hepatoma cells, might be decreased in HCC patients livers. The hypothesis of this study was whether miR-122 plays a role in inflammatory pathways through regulating TLR4 expression in hepatoma cells.

Methods: The expression of miR-122 in the tissues of HCC patients compared to controls in TCGA datasets was analyzed. The relationship between miR-122 and TLR4 was detected in HCC cell lines by increasing/decreasing miR122 expression. The target of miR-122 on TLR4 was confirmed by luciferase reporter assays. The proliferation of HCC cells and production of proinflammatory cytokines were measured with miR-122 upregulation and inhibition.

Results: We found that the expression of miR-122 was decreased in HCC tissues and showed the diagnostic capacity for HCC in TCGA datasets. MiR-122 and TLR4 expression have negative correlation in normal liver cells and HCC cells. Upregulation of miR-122 significantly inhibited TLR4 expression in hepatoma cells, including in hepatoma cells with the induction of LPS, while knocking down miR-122 increased TLR4 expression. By screening potential miR-122 targets among TLR4, we found that there was a putative miR-122 target in TLR4 3'UTR. Mutations in the nt1603-nt1609 region of TLR4 3'UTR abandoned the impact of miR-122 on TLR4 expression. Over-expression/downexpression of miR-122 could influence the proliferation and the expression of natural immune factors.
\end{abstract}

Conclusions: MiR-122 might target TLR4 and regulate host innate immunity in hepatoma cells, which revealed a new molecular mechanism of miR-122 on the regulation of innate immunity.

Keywords: MiRNA, miR-122, Toll like receptor, Hepatocytes

\section{Background}

Hepatocellular carcinoma (HCC) is considered to be one of the most common malignancies in the world, which influences our health [1]. Up to now, there is not effective therapy strategy for HCC [2] because the pathogenic mechanism of HCC is highly complicated [3]. The tumorigenesis of HCC involves multistage processes, and it has been reported that abnormal Toll-like receptor (TLR)

\footnotetext{
* Correspondence: junqian1978@163.com
+Liyu Shi and Xiaoqiu Zheng contributed equally to this work.

* Correspondence: junqian1978@163.com
+Liyu Shi and Xiaoqiu Zheng contributed equally to this work.

'Department of Microbiology, Harbin Medical University, No. 194, Xuefu Road, Harbin 150081, Heilongjiang province, China

${ }^{2}$ Wu Lien-Teh institutes, Harbin Medical University, Harbin, Heilongjiang province, China
}

(c) The Author(s). 2019 Open Access This article is distributed under the terms of the Creative Commons Attribution 4.0 International License (http://creativecommons.org/licenses/by/4.0/), which permits unrestricted use, distribution, and reproduction in any medium, provided you give appropriate credit to the original author(s) and the source, provide a link to the Creative Commons license, and indicate if changes were made. The Creative Commons Public Domain Dedication waiver (http://creativecommons.org/publicdomain/zero/1.0/) applies to the data made available in this article, unless otherwise stated. and progression of HCC [4].

TLRs are mainly expressed in immune cells and play an important role in the homeostasis of the human immune system [5]. However, more evidence suggest that TLRs can also be expressed in many kinds of tumor cells, and the signaling pathways of TLRs can be associated with the progression of $\mathrm{HCC}$ through affecting the proliferation of tumor cells, evasion of immune surveillance and drug resistant [6-9]. For example, TLR4 can promote tumor development in human head and neck squamous cell carcinoma [10]. TLR4 signaling pathway could also induce COX-2/PGE2/STAT3 positive feedback loop to regulate the proliferation and drug resistance of HCC [11]. Recent 
research demonstrated that high expression of TLR4 was associated with microvascular invasion in HCC [12]. These observations indicate TLR4 displays critical roles in HCC progression.

MiR-122 is the most abundant miRNA in hepatocytes, which can be involved in hepatocyte proliferation, apoptosis and related with HCC [13-15]. It could directly target cyclin G1 [16], anti-apoptosis gene Bcl-w [17], WNT1 gene in WNT signaling pathway [18], etc. The decreasing effect of miR-122 in a subset of HCC characterized by poor prognosis was reported [19]. MiR-122 could also regulate IFN expression, which suggested that miR-122 might have a novel function and therapeutic application in hepatocarcinogenesis [20].

In this study, we examined the associations between miR-122 and TLR4 in HCC. Our data suggest that miR122 modulates host's innate immunity through blocking TLR4 and may play important role in the carcinogenesis in the liver.

\section{Methods}

MiR-122 expression in HCC samples from TCGA database In this study, we examined miR-122 expression in $\mathrm{HCC}$ tissues by searching TCGA database (https://cancergenome.nih.gov/). We obtained the miRNA profiles of 372 HCC tissues and 49 control tissues. Afterward, miR-122 expression was examined from the miRNA profiles.

\section{Cell culture}

Human hepatocellular carcinoma cell lines HepG2, Huh7, human normal LO2 cells and $293 \mathrm{~T}$ (Harbin Medical University) were cultured in Dulbecco's modified Eagle's medium (DMEM) supplemented with 10\% fetal bovine serum (FBS) (Gibco, USA). Cell were incubated at $37^{\circ} \mathrm{C}$ in a humidified atmosphere with $5 \% \mathrm{CO}_{2}$.

\section{MiRNA target prediction}

The potential targets of miR-122 in the TLR4 3'UTR were predicted by TargetScan- Human 7.1 (targetscan.org/vert_71) and miRanda (microrna.org/microrna/home.do) based on the complementary sequences.

\section{Nucleotides, plasmids, and LPS}

The sense and anti-sense miR-122 mimic (5' -TGGAGT GTGACAATGGTGTTTG-3', 5' -CAAACACCAUUGUC ACACUCCA-3'), the 2'-O-methylated, anti-miR-122 oligo- nucleotide (AMO-122) (5'-CAAACACCAUUGUC ACACUCCA-3'), and the negative controls were synthesized (GenePharma, China). The pmiR-RB-REPORT ${ }^{\text {тm }}$ TLR4 (RIBOBIO, China) and Lipopolysaccharides (Sigma, USA) were obtained respectively.

\section{Cell treatment and transfection}

HepG2, Huh7 and LO2 cell lines were seeded for 24 $h$, and transiently transfected with nucleotides/plasmids according to the instructions of Lipofectamine 2000 (Invitrogen, USA), followed by treatment with $10 \mu \mathrm{g} / \mathrm{mL}$ LPS (Sigma, USA). Cells were used for RNA and protein extractions $48 \mathrm{~h}$ post-transfection.

\section{RNA isolation and quantitative real-time PCR}

Total RNA was extracted from HepG2, Huh7 and LO2 cells using TRIzol reagent (Invitrogen, USA), followed by reverse transcription. Quantitative real-time PCR (qPCR) was performed with SYBR PrimeScript Ex Taq (TaKaRa, Japan) according to manufacturer's instructions. Relative expression levels were determined and were normalized to that of glyceraldehyde 3-phosphate dehydrogenase (GAPDH) and U6. Three duplicate wells were set for all reactions. The relative expression was calculated based on the formula $2(-\Delta \Delta \mathrm{Ct}) . \Delta \Delta \mathrm{Ct}$ values are $\Delta C \mathrm{t}$ exp. $-\Delta \mathrm{Ct}$ cont. The primers used were showed as followed (Table 1).

\section{Western blot analysis}

Total proteins were extracted by Pierce RIPA Buffer (Thermo) and separated by $12 \%$ SDS- polyacrylamide gel electrophoresis. A polyclonal TLR4 antibody (Cell Signaling Technology, USA) and the polyclonal antibody against Actin (Zhongshan Golden Bridge, China) were used for immunoblotting detection. The blots were stained with a SuperSignal kit (Pierce, Rockford, IL) and photographed by LAS4000 (Fujifilm, Japan). The ratio of TLR4 to Actin was used as a quantitative measurement of TLR4 regulation by miR-122.

\section{MTT}

Cell proliferation was identified using the 3-(4,5-dimethylthiazol-2-yl)-2,5-diphenyl tetrazolium.

Table 1 Sequences of real-time PCR primers used in this study

\begin{tabular}{ll}
\hline Gene & Primer Sequences(5'-3') \\
\hline TLR4 & F: 5'-TTGAGCAGGTCTAGGGTGATTGAAC-3' \\
R: 5'-ATGCGGACACACACACTTTCAAATA-3' & F: 5'-ATCACTGCCACCCAGAAGAC-3' \\
miR-122 & R: 5'-TTTCTAGACGGCAGGTCAGG-3' \\
& RT: 5'-GTCGTATCCAGTGCGTGTCGTGGAGTCGGCAATTGC \\
& F: 5'-GGGTGG AGTGTGACA ATGG-3' \\
& R: 5'-TGCGTGTCGTGGAGTC-3' \\
& RT: 5'-CGCTTCACGAATTTGCGTGTCAT-3' \\
& F: 5'-GCTTCGGCAGCACATATACTAAAAT-3' \\
& R: 5'-CGCTTCACGAATTGCGTGTCAT-3'
\end{tabular}


bromide assay (MTT). Cell proliferation was evaluated at 24,48 and $72 \mathrm{~h}$ after transfection. The absorbance of the samples was determined at $490 \mathrm{~nm}$. Three independent repeated experiments were performed.

\section{Plasmids construction}

Genomic DNA was extracted in $293 \mathrm{~T}$ cells as a template, and TLR4 3'UTR gene fragment was amplified. According to the predicted binding of miR-122 and TLR4 3' UTR, mutant types of TLR4 3'UTR were designed: TLR4 3'UTR-m1. The primers included primer wild (F: 5'-GGCG GCTCGAGGTTCATCCAGCCTCCTC AG-3', R: 5' - AATGCGGCCGCCTCATTTCTCCCTTC CTCC-3'), primer mutant (F: 5'-AAATATT TTGTGAGG CATGTTCATTGTGGCACT-3'， R: 5'-TGAACATGCC TCACAAAATATTTTCTTGAAATT-3'). The TLR4 3' UTR/TLR4 3'UTR- $\mathrm{m} 1$ transcript was cloned into the Xhol/NotI sites in the pmiR-RB-REPORT T ${ }^{\text {To }}$ plasmid. For mutation analysis, we substituted the 7-nt core seedmatched site (ACACTCC) with complementary bases (TGTGAGG). The mutations in these plasmids were verified by DNA sequencing.

\section{Reporter assay}

$293 \mathrm{~T}$ cells were co-transfected with miR-122/miRNAcontrol and TLR4-WT plasmid/TLR4- MUT plasmid using Lipofectamine 2000. After $48 \mathrm{~h}$, the cells were collected for application in the reporter system (Promega, USA) following the manufacturer's instructions. All dual- luciferase reporter assays were carried out in triplicate within each experiment, and three independent experiments were conducted.

\section{Elisa}

The productions of IL- 6 and TNF- $\alpha$ in culture supernatant were measured using the Human IL- 6 and TNF- $\alpha$ ELISA kits (Mlbio, China) according to the manufacturer's instructions.

\section{Statistical analysis}

Measurement data were represented as the mean \pm standard error of the mean (SEM). Statistical analysis was performed using SigmaStat 3.0 (Systat Software, USA). The Student's $t$ test was used to evaluate the differences between two groups. When $P<0.05$, the difference was considered to have statistical significance.

\section{Results \\ Expression of miR-122 in HCC from TCGA database}

A total of $372 \mathrm{HCC}$ cases and 49 adjacent control cases were collected from TCGA database. MiR-122 expression was decreased in the HCC group in comparison with the control group $(p<0.01)$ (Fig. 1a). The ROC curve assessed the diagnostic ability of miR-122 (AUC = 0.823, $p<0.0001$ ) (Fig. 1b).

\section{The expression of miR-122 is downregulated and TLR4 was upregulated in hepatocytes}

Previous studies showed that miR-122 downregulated in HCC tissue, while TLR4 levels varied between specimens. These findings imply that expression of miR-122 and TLR4 is inversely related in HCC. To ascertain the relationship between miR-122 and TLR4 in hepatocytes, we first compared their expression levels in human HCC cell lines Huh7 and human normal liver cells LO2. The results showed that miR-122 was over-expressed in LO2 cells in comparison with HCC Huh7 cells (Fig. 2a), which indicated that miR-122 might display a crucial role in hepatoma development. We next examined the TLR4 mRNA and protein expression by qPCR and western blot. The expression of TLR4 was found to be obviously up-regulated in HCC Huh7 cells compared with the LO2 cells, which was opposite to the expression level of miR-122 (Fig. 2b and c). This further suggested that TLR4 might have the negative correlation with miR-122 abundances in hepatocytes.
A

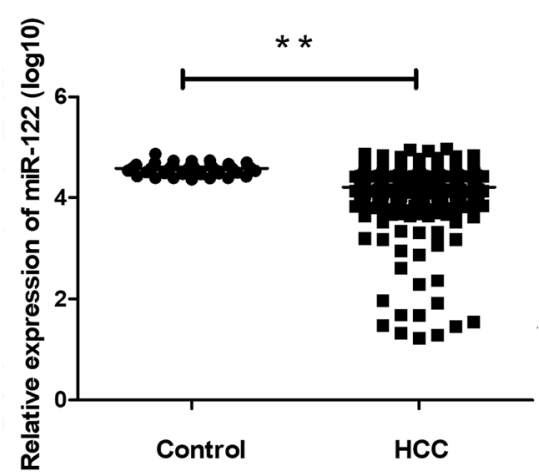

B

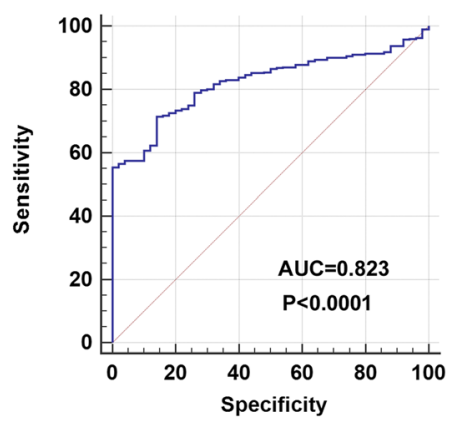

Fig. 1 MiR-122 expression in TCGA samples and the diagnostic value. a The expression of miR-122 in 372 HCC and 49 control tissues. b The ROC curve was generated to assess the diagnostic ability of miR-122 in HCC and control tissues. The AUC was $0.823(p<0.001)$. $(\mathrm{AUC}=0.823, p<0.0001)$ 
A

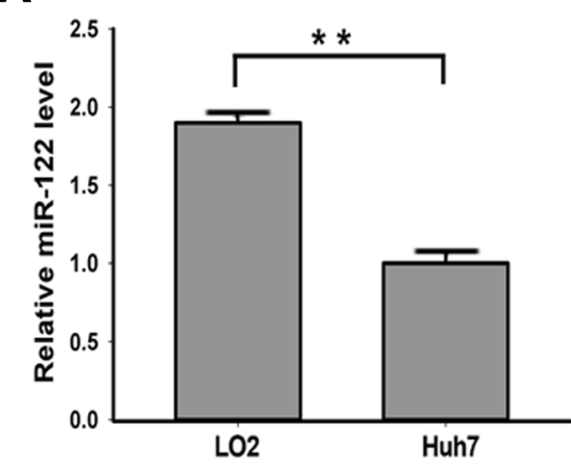

C

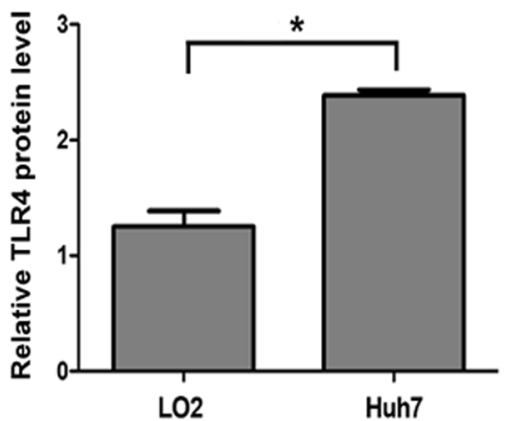

B

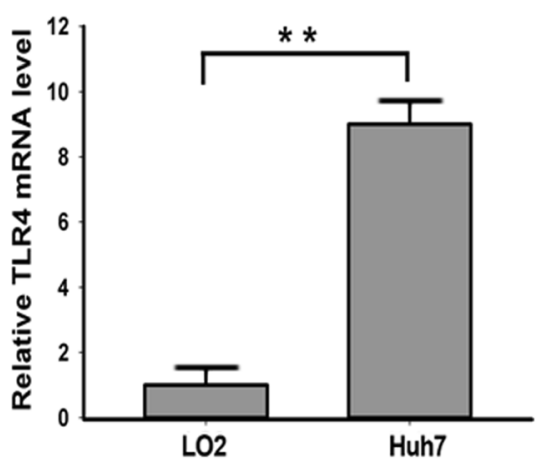

Huh7

TLR4

LO2

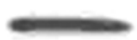

Actin

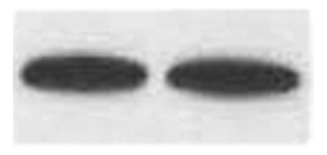

Fig. 2 The expression of miR-122 is downregulated and TLR4 was upregulated in hepatocytes. $\mathbf{a}$ and $\mathbf{b}$ qPCR analysis of the relative miR-122 and TLR4 mRNA levels in hepatoma cells Huh7 compared with the normal human hepatocyte LO2 cells. c Western blot was used to measure the expression of TLR4, and beta-actin was used as an internal control. Values are presented as the mean $\pm \operatorname{SEM}(n=3)$. ${ }^{*} P<0.05,{ }^{* *} P<0.01$

\section{MiR-122 could suppress the TLR4 expression}

To verify whether the expression of TLR4 could be regulated by miR-122, HepG2 cells were transfected with miR-122 mimic/AMO-122 and negative controls (NC) to determine the mRNA and protein expression levels of TLR4 by qPCR and western blotting, respectively. The level of miR-122 expression was examined first after transfection (Fig. 3a), which suggested that miR-122 mimic or AMO-122 could increase or reduce the expression of miR-122 and could be used in the following experiments. The mRNA and protein level of TLR4 was significantly downregulated in the miR-122-overexpressing HepG2 cells compared with the NC-transfected cells $(P<0.05)$ (Fig. $3 \mathrm{~b}$ and $\mathrm{c}$ ). These findings demonstrated that miR-122 may inhibit TLR4 expression in hepatocytes.

LPS can stimulate TLR4, leading to the high expression of TLR4 after LPS treatment, so the expressions of TLR4 and miR-122 were detected to identify the relationship between them. The results showed that miR-122 was downregulated and TLR4 was up-regulated (Fig. 3d and e). To validate the influence of miR-122 on TLR4 expression in hepatocytes, miR-122 mimic was transfected to LO2 cells to reverse the decrease of miR-122, followed by LPS stimulation. The expression of miR-122 increased/decreased with
miR-122 mimic/AMO-122 transfection after LPS treatment (Fig. 3f), and TLR4 expression was opposite to that of miR122 (Fig. $3 \mathrm{~g}$ and $\mathrm{h}$ ), which were consistent with that of miR-122 mimic and AMO-122 transfection (Fig. 3b and c). These results confirm that miR-122 specifically suppresses the TLR4 expression.

\section{Prediction and confirmation of miR-122 targets in the TLR4 3'UTR}

To verify our hypothesis, we used the Targetscan and miRanda, web-based miRNA analysis tools, to screen potential miR-122 targets in TLR4 3'UTR. Interestingly, the analysis results indicated that there were 13 putative miR-122 binding sites located in the 3'UTR of TLR4 transcript and the target sequence was perfectly matched to the seed sequence of miR-122, which located in nt1603-nt1609 of TLR4 3'UTR (Fig. 4a). To clarify the interaction between miR-122 and TLR4 3'UTR, sequences corresponding to miR-122 seed binding sites were constructed. pmiR-RB-REPORT ${ }^{\mathrm{TM}}$ plasmids containing wild and mutated TLR4 3'UTR (TLR4-WT and TLR4-MUT) were generated by PCR. The TLR4-MUT plasmid contained mismatches in the common miR-122 seed region, and seven nucleotides between nt1603 and nt1609 were substituted from ACACTCC to TGTG 


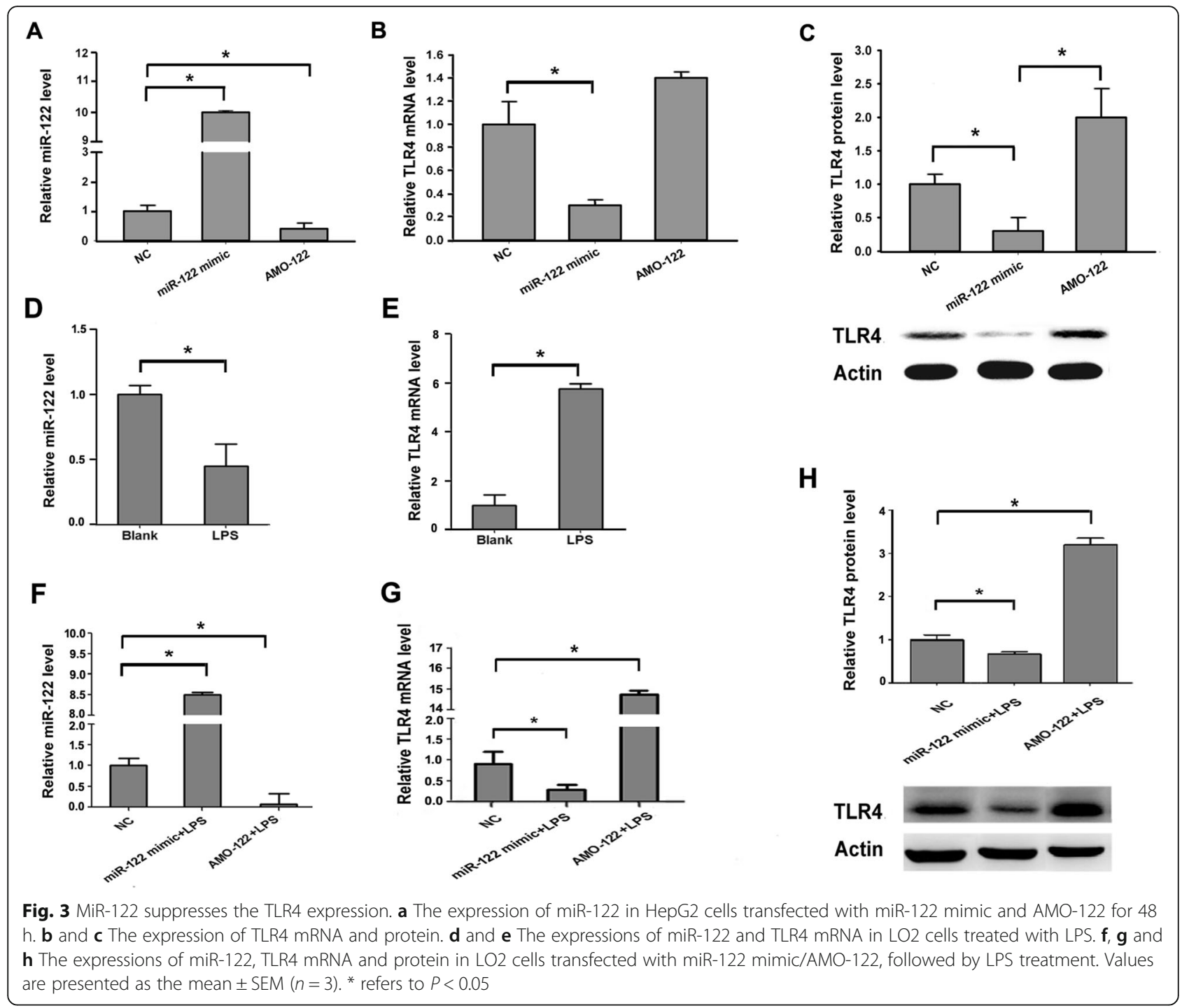

AGG (Fig. 4b). Mutations in this region should block miR-122 binding and abrogate the miR-122-mediated repression of TLR4 expression. Using the same protocol above, miR-122 mimic and negative control were separately co-transfected into $293 \mathrm{~T}$ cells with TLR4-WT or TLR4-MUT. The TLR4 expression was measured by luciferase assay. Cells containing the TLR4-WT showed a significant and repeatable decrease in activity in the presence of mimics of miR122 compared with the negative control (Fig. 4c). This suggested that TLR4 may be a miR-122 target. In contrast, the TLR4-MUT was co-transfected into $293 \mathrm{~T}$ cells with miR-122 mimic or a negative control. The expression of TLR4 did not change significantly upon treatment with mimics of miR-122 (Fig. 4c). These results demonstrated that miR-122 downregulated TLR4 expression via direct binding to site 1603-1609 in the 3'UTR of TLR4.
MiR-122 negatively regulates the proliferation of HCC cells and production of Proinflammatory cytokines

To analyze whether miR-122 expression could regulate HCC cells proliferation, we transfected miR-122 mimic into HepG2 cells and AMO-122 into Huh7 cells. MTT results showed that increasing of miR-122 inhibited HepG2 cells proliferation, however, decreasing of miR-122 promoted Huh7 cells proliferation (Fig. 5a and b). To assess whether miR-122 may be involved in the regulation of innate response in the pathways, we also analyzed the expression of proinflammatory cytokines. MiR-122 overexpression/inhibition significantly inhibited/increased TNF- $\alpha$ and IL-6 production (Fig. 5a and b). These results indicated that miR-122 might act as a negative regulator of proliferation and TLR-triggered innate inflammatory response by suppressing the production of proinflammatory cytokines such as IL- 6 and TNF- $\alpha$. 


\section{A hsa-miR-122 \\ 3'GUUUGUGguACAGUgUGAgGU5' \\ mirSVR score: $-\mathbf{0 . 6 3 1 2}$ TLR4 3'UTR \\ B TLR4-MUT(nt1603-nt1609) 5'AAUAUUUUUGU'GÁG'́c, \\ I I I I I: । I । । I I I Phastcons score: 0.5175 5'UUCAAGAAAAUAUUUACACUCCC3'}

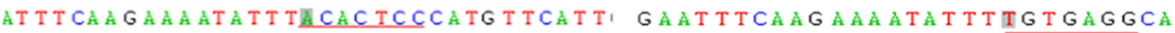

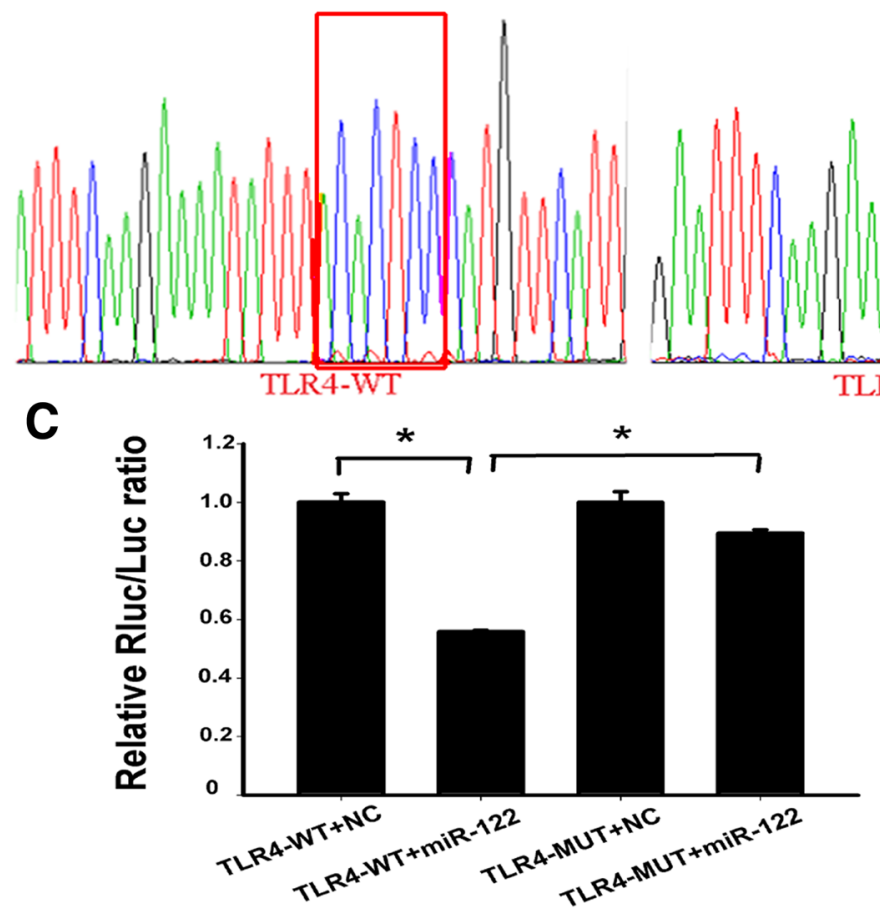

Fig. 4 MiR-122 directly binds to the $3^{\prime} U T R$ of TLR4 transcript. a Prediction of miR-122 targets in TLR4 $3^{\prime} U T R$. The complementary sequences between miR-122 and TLR4 3'UTR (GenBank accession: NM_138554.4). b The mutated nucleotides in the putative targets of TLR4 and the sequencing data of the mutated pTLR4-MUT. The pTLR4-MUT were generated to minimize the match of miR-122 with TLR4 3'UTR in the region of nt1603-nt1609. The red boxes are the mutated regions. c MiR-122 mimic was co-transfected into 293 T cells with TLR4-WT or TLR4-MUT plasmid, respectively. TLR4 expression in the treated cells was observed at $48 \mathrm{~h}$ post-transfection. Values are presented as the mean \pm SEM $(n=4)$. * refers to $P<0.05$, ** refers to $P<0.01$

\section{Discussion}

TLR4 was functionally expressed on HCC cells, and many liver cells (Kupffer cells, hepatocytes, activated stellate cells) constantly express TLR4 [8, 21-24]. The expression of TLR4 was significantly increased in HBV- and HCV-infected livers, as well as in HCC tissues [25-28]. TLR4 signaling pathway induced by LPS can be associated with the survival and proliferation of cancer cells in HCC $[29,30]$. TLR4 activation subsequently activates the downstream signaling pathways, leading to the expression of proinflammatory cytokines [31]. Several inflammatory mediators, such as TNF- $\alpha$, IL- 6 , and IL-10, might have an effect in the initiation and progression of cancer [32], so the inflammatory microenvironment can be relate to the tumorigenesis of liver [33]. IL-6 is one of the proinflammatory cytokines, which have a typical protumorigenic effect [32]. IL-6 can activate signal transducer and activator of transcription 3 (STAT3) and upregulate the transcription of SOCS3 [34].
The activation of JAK/STAT3 pathways might be involved in HCC progression [35]. Notably, the upregulation of IL-6 in human HCC was shown to induce tumor development [36-38]. Tumor necrosis factor (TNF- $\alpha$ ) is also one important inflammatory mediator that has been implicated in carcinogenesis [32, 39].

MiR-122, a liver-specific miRNA in human, is decreased in HCC tissues and plays a pivotal role in regulating the metabolism and hepatocarcinogenesis [40-44]. Silencing miR-122 can also induce the dedifferentiation of hepatocytes [45]. MiR-122 might be an intrinsic tumor suppressor gene $[44,46-48]$ and have an anti-inflammatory role in HCC [42]. Some results showed that some exosome-transported miRNAs can inhibit HCC growth in SCID mice [23, 49,50], which might be one of the modes of the effect of miR-122. Furthermore, IL-6 and TNF- $\alpha$ can markedly decrease the expression level of miR-122 [51]. All these revealed that miR-122 may 
A

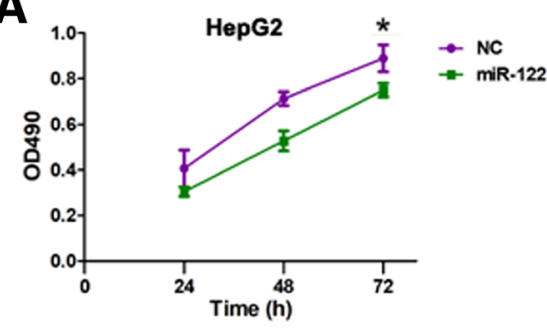

C

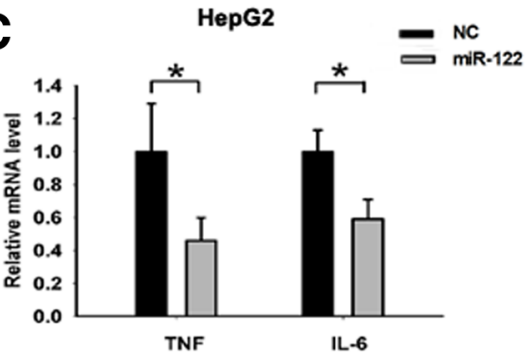

E

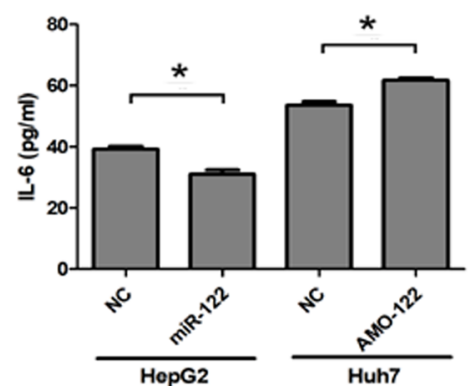

B
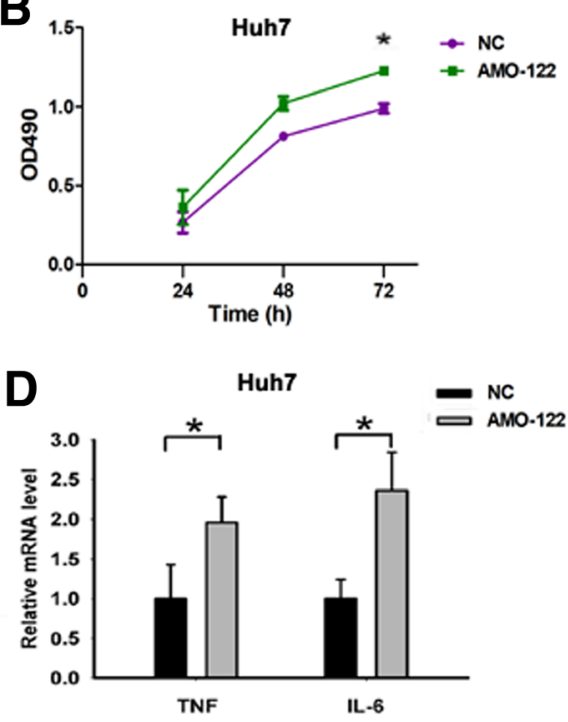

$\mathbf{F}$

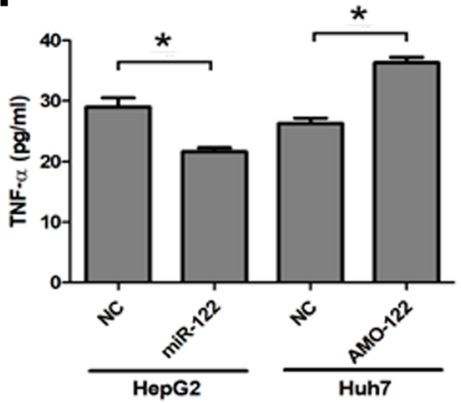

Fig. 5 MiR-122 suppresses the proliferation and production of proinflammatory cytokines. a The proliferation of HepG2 cells was detected by MTT after transfecting with miR-122 mimic. b The proliferation of Huh7 cells was detected by MTT after transfecting with AMO-122. c The expression of TNF- $a$ and IL-6 in HepG2 cells transfected with miR-122 mimic for $48 \mathrm{~h}$. $\mathbf{d}$ The expression of TNF-a and IL-6 in Huh7 cells transfected with AMO-122 for 48 h. e, f The expression of IL-6 and TNF-a in HepG2/Huh7 cells transfected with miR-122 mimic/AMO- 122. Values are presented as the mean $\pm \operatorname{SEM}(n=3) .{ }^{*} P<0.05,{ }^{*} P<0.01$

have therapeutic potential for preventing the progression of liver diseases [52].

The results of our study showed that miR-122 was downregulated and TLR4 was upregulated in HCC cell lines, which was consistent with the results in many reports. All these demonstrated a negative regulatory relationship between miR-122 and TLR4 in hepatocellular cell lines. These results are consistent with the study which transient transfected miR-122 mimic into HepG2 cells caused a decrease in TLR4 protein level. MiR-122 can also suppress the TLR4 expression with LPS stimulation in LO2 cells. We confirmed that miR-122 directly bound to the 3'UTR of the TLR4 transcript and further suppress the translation of TLR4 by a luciferase reporter assay. In addition, we also examined the expression of IL-6 and TNF- $\alpha$. As a TLR4 common downstream cytokine, the expression of IL- 6 and TNF- $\alpha$ were also significantly down-regulated after intervention with mimics. Accordingly, we believe that miR-122 attenuates TLR4 signaling pathway via targeting TLR4 directly.

\section{Conclusions}

In conclusion, our results indicated that miR-122 repressed the expression of TLR4 by binding to the 3' UTR of TLR4. Downregulating the expression of miR122 could promote the expression of TLR4. The upregulation of miR-122 could regulate host innate immunity by TLR4 in hepatoma cells, which will provide a strategy for cancer treatment.

\section{Abbreviations}

AMO-122: Anti-miR-122 oligonucleotide; GAPDH: Glyceraldehyde-3phosphate dehydrogenase; HCC: Hepatocellular carcinoma; IL: Interleukin; QRT-PCR: Quantitative RT-PCR; ROC: Receiver operation characteristic; SEM: Standard error of the mean; TLR: Toll-like receptor; TNF: Tumor necrosis factor

Acknowledgements None. 


\section{Authors' contributions}

QJ designed the study. SL and ZX contributed the analysis of TCGA datasets and targets confirmation. FY contributed to the testing of TLR4. YX and LA contributed to data analysis. SL, ZX and QJ drafted and wrote the manuscript. All authors read and approved the final manuscript.

\section{Funding}

This work was supported by the National Natural Science Foundation of China (NSFC) (81202296) and Heilongjiang Postdoctoral Grant (LBH-Q15083) in study design, data analysis, and publication.

\section{Availability of data and materials}

The datasets generated and analyzed during the current study are available from the corresponding author on reasonable request.

\section{Ethics approval and consent to participate}

No clinical patients samples were collected in this study.

\section{Consent for publication}

Not applicable.

\section{Competing interests}

The authors declare that they have no competing interests.

Received: 2 January 2019 Accepted: 17 July 2019

Published online: 24 July 2019

\section{References}

1. Ma J, Li T, Han X, Yuan H. Knockdown of LncRNA ANRIL suppresses cell proliferation, metastasis, and invasion via regulating miR-122-5p expression in hepatocellular carcinoma. J Cancer Res Clin Oncol. 2018;144(2):205-14.

2. Gao JJ, Shi ZY, Xia JF, Inagaki Y, Tang W. Sorafenib-based combined molecule targeting in treatment of hepatocellular carcinoma. World J Gastroenterol. 2015;21(42):12059-70.

3. Yin Y, Li F, Li S, Cai J, Shi J, Jiang Y. TLR4 influences hepatitis B virus related hepatocellular carcinoma by regulating the Wnt/beta-catenin pathway. Cell Physiol Biochem. 2017:42(2):469-79.

4. Ren X, Wang F, Ji B, Gao C. TLR7 agonist induced repression of hepatocellular carcinoma via the TLR7-IKK-NF-kappaB-IL6 signaling pathway. Oncol Lett. 2016;11(5):2965-70.

5. Lavelle EC, Murphy C, O'Neill LA, Creagh EM. The role of TLRs, NLRs, and RLRs in mucosal innate immunity and homeostasis. Mucosal Immunol. 2010; 3(1):17-28.

6. Huang B, Zhao J, Li H, He KL, Chen Y, Chen SH, Mayer L, Unkeless JC, Xiong $\mathrm{H}$. Toll-like receptors on tumor cells facilitate evasion of immune surveillance. Cancer Res. 2005;65(12):5009-14.

7. Kelly MG, Alvero AB, Chen R, Silasi DA, Abrahams VM, Chan S, Visintin I, Rutherford T, Mor G. TLR-4 signaling promotes tumor growth and paclitaxel chemoresistance in ovarian cancer. Cancer Res. 2006;66(7):3859-68.

8. Yang J, Li M, Zheng QC. Emerging role of toll-like receptor 4 in hepatocellular carcinoma. J hepatocell Carcinoma. 2015;2:11-7.

9. Liu Y, Li T, Xu Y, Xu E, Zhou M, Wang B, Shen J. Effects of TLR4 gene silencing on the proliferation and apotosis of hepatocarcinoma HEPG2 cells. Oncol Lett. 2016;11(5):3054-60.

10. Szczepanski MJ, Czystowska M, Szajnik M, Harasymczuk M, Boyiadzis M, Kruk-Zagajewska A, Szyfter W, Zeromski J, Whiteside TL. Triggering of tolllike receptor 4 expressed on human head and neck squamous cell carcinoma promotes tumor development and protects the tumor from immune attack. Cancer Res. 2009;69(7):3105-13.

11. Lin A, Wang G, Zhao H, Zhang Y, Han Q, Zhang C, Tian Z, Zhang J. TLR4 signaling promotes a COX-2/PGE2/STAT3 positive feedback loop in hepatocellular carcinoma (HCC) cells. Oncoimmunology. 2016;5(2):e1074376.

12. Liu WT, Jing YY, Yu GF, Han ZP, Yu DD, Fan QM, Ye F, Li R, Gao L, Zhao QD, et al. Toll like receptor 4 facilitates invasion and migration as a cancer stem cell marker in hepatocellular carcinoma. Cancer Lett. 2015;358(2):136-43.

13. Xu J, Zhu X, Wu L, Yang R, Yang Z, Wang Q, Wu F. MicroRNA-122 suppresses cell proliferation and induces cell apoptosis in hepatocellular carcinoma by directly targeting Wnt/beta-catenin pathway. Liver Int. 2012; 32(5):752-60.

14. Chang J, Nicolas E, Marks D, Sander C, Lerro A, Buendia MA, Xu C, Mason WS, Moloshok T, Bort R, et al. miR-122, a mammalian liver-specific
microRNA, is processed from hcr mRNA and may downregulate the high affinity cationic amino acid transporter CAT-1. RNA Biol. 2004;1 (2):106-13.

15. Shyu YC, Lee TL, Lu MJ, Chen JR, Chien RN, Chen HY, Lin JF, Tsou AP, Chen $\mathrm{YH}$, Hsieh CW, et al. miR-122-mediated translational repression of PEG10 and its suppression in human hepatocellular carcinoma. J Translat Med. 2016;14(1):200.

16. Gramantieri L, Ferracin M, Fornari F, Veronese A, Sabbioni S, Liu CG, Calin GA, Giovannini C, Ferrazzi E, Grazi GL, et al. Cyclin G1 is a target of miR122a, a microRNA frequently down-regulated in human hepatocellular carcinoma. Cancer Res. 2007;67(13):6092-9.

17. Lin CJ, Gong HY, Tseng HC, Wang WL, Wu JL. miR-122 targets an antiapoptotic gene, Bcl-w, in human hepatocellular carcinoma cell lines. Biochem Biophys Res Commun. 2008;375(3):315-20.

18. Ahsani Z, Mohammadi-Yeganeh S, Kia V, Karimkhanloo H, Zarghami N, Paryan M. WNT1 gene from WNT signaling pathway is a direct target of miR-122 in hepatocellular carcinoma. Appl Biochem Biotechnol. 2017; 181(3):884-97.

19. Coulouarn C, Factor VM, Andersen JB, Durkin ME, Thorgeirsson SS. Loss of miR-122 expression in liver cancer correlates with suppression of the hepatic phenotype and gain of metastatic properties. Oncogene. 2009; 28(40):3526-36.

20. Li A, Song W, Qian J, Li Y, He J, Zhang Q, Li W, Zhai A, Kao W, Hu Y, et al. MiR-122 modulates type I interferon expression through blocking suppressor of cytokine signaling 1. Int J Biochem Cell Biol. 2013;45(4):858-65.

21. Matsumura T, Degawa T, Takii T, Hayashi H, Okamoto T, Inoue J, Onozaki K. TRAF6-NF-kappaB pathway is essential for interleukin-1-induced TLR2 expression and its functional response to TLR2 ligand in murine hepatocytes. Immunology. 2003;109(1):127-36.

22. Paik YH, Schwabe RF, Bataller R, Russo MP, Jobin C, Brenner DA. Toll-like receptor 4 mediates inflammatory signaling by bacterial lipopolysaccharide in human hepatic stellate cells. Hepatology. 2003;37(5):1043-55.

23. Su GL, Klein RD, Aminlari A, Zhang HY, Steinstraesser L, Alarcon WH, Remick DG, Wang SC. Kupffer cell activation by lipopolysaccharide in rats: role for lipopolysaccharide binding protein and toll-like receptor 4. Hepatology. 2000;31(4):932-6.

24. Testro AG, Visvanathan $\mathrm{K}$. Toll-like receptors and their role in gastrointestinal disease. J Gastroenterol Hepatol. 2009;24(6):943-54.

25. Wang JP, Zhang Y, Wei X, Li J, Nan XP, Yu HT, Li Y, Wang PZ, Bai XF. Circulating toll-like receptor (TLR) 2, TLR4, and regulatory T cells in patients with chronic hepatitis C. APMIS. 2010;118(4):261-70.

26. Wei XQ, Guo YW, Liu JJ, Wen ZF, Yang SJ, Yao JL. The significance of tolllike receptor 4 (TLR4) expression in patients with chronic hepatitis B. Clin Invest Med. 2008;31(3):E123-30.

27. Machida K, Tsukamoto H, Mkrtchyan H, Duan L, Dynnyk A, Liu HM, Asahina K, Govindarajan S, Ray R, Ou JH, et al. Toll-like receptor 4 mediates synergism between alcohol and HCV in hepatic oncogenesis involving stem cell marker Nanog. Proc Natl Acad Sci U S A. 2009;106(5):1548-53.

28. Nishimura M, Naito $\mathrm{S}$. Tissue-specific mRNA expression profiles of human toll-like receptors and related genes. Biol Pharm Bull. 2005;28(5):886-92.

29. Wang L, Zhu R, Huang Z, Li H, Zhu H. Lipopolysaccharide-induced toll-like receptor 4 signaling in cancer cells promotes cell survival and proliferation in hepatocellular carcinoma. Dig Dis Sci. 2013;58(8):2223-36.

30. Yuan X, Zhou Y, Wang W, Li J, Xie G, Zhao Y, Xu D, Shen L. Activation of TLR4 signaling promotes gastric cancer progression by inducing mitochondrial ROS production. Cell Death Dis. 2013;4:e794.

31. Loiarro M, Ruggiero V, Sette C. Targeting TLR/L-1R signalling in human diseases. Mediat Inflamm. 2010;2010:674363.

32. Landskron G, De la Fuente M, Thuwajit P, Thuwajit C, Hermoso MA. Chronic inflammation and cytokines in the tumor microenvironment. J Immunol Res. 2014;2014:149185.

33. Jin K, Li T, Sanchez-Duffhues G, Zhou F, Zhang L. Involvement of inflammation and its related microRNAs in hepatocellular carcinoma. Oncotarget. 2017;8(13):22145-65.

34. Serrano-Marco L, Barroso E, El Kochairi I, Palomer X, Michalik L, Wahli W, Vazquez-Carrera M. The peroxisome proliferator-activated receptor (PPAR) beta/delta agonist GW501516 inhibits IL-6-induced signal transducer and activator of transcription 3 (STAT3) activation and insulin resistance in human liver cells. Diabetologia. 2012;55(3):743-51.

35. Calvisi DF, Ladu S, Gorden A, Farina M, Conner EA, Lee JS, Factor VM, Thorgeirsson SS. Ubiquitous activation of Ras and Jak/stat pathways in human HCC. Gastroenterology. 2006;130(4):1117-28. 
36. He G, Dhar D, Nakagawa H, Font-Burgada J, Ogata H, Jiang Y, Shalapour S, Seki $\mathrm{E}$, Yost $\mathrm{SE}$, Jepsen $\mathrm{K}$, et al. Identification of liver cancer progenitors whose malignant progression depends on autocrine IL-6 signaling. Cell. 2013;155(2):384-96.

37. Hirsch HA, lliopoulos D, Struhl K. Metformin inhibits the inflammatory response associated with cellular transformation and cancer stem cell growth. Proc Natl Acad Sci U S A. 2013;110(3):972-7.

38. Toffanin S, Friedman SL, Llovet JM. Obesity, inflammatory signaling, and hepatocellular carcinoma-an enlarging link. Cancer Cell. 2010;17(2):115-7.

39. Popa C, Netea MG, van Riel PL, van der Meer JW, Stalenhoef AF. The role of TNF-alpha in chronic inflammatory conditions, intermediary metabolism, and cardiovascular risk. J Lipid Res. 2007;48(4):751-62.

40. Hou J, Lin L, Zhou W, Wang Z, Ding G, Dong Q, Qin L, Wu X, Zheng Y, Yang $Y$, et al. Identification of miRNomes in human liver and hepatocellular carcinoma reveals miR-199a/b-3p as therapeutic target for hepatocellular carcinoma. Cancer Cell. 2011;19(2):232-43.

41. Jopling C. Liver-specific microRNA-122: biogenesis and function. RNA Biol. 2012;9(2):137-42

42. Tsai WC, Hsu SD, Hsu CS, Lai TC, Chen SJ, Shen R, Huang Y, Chen HC, Lee $\mathrm{CH}$, Tsai TF, et al. MicroRNA-122 plays a critical role in liver homeostasis and hepatocarcinogenesis. J Clin Invest. 2012;122(8):2884-97.

43. Takaki Y, Saito Y, Takasugi A, Toshimitsu K, Yamada S, Muramatsu T, Kimura M, Sugiyama K, Suzuki H, Arai E, et al. Silencing of microRNA-122 is an early event during hepatocarcinogenesis from non-alcoholic steatohepatitis. Cancer Sci. 2014;105(10):1254-60.

44. Liu AM, Xu Z, Shek FH, Wong KF, Lee NP, Poon RT, Chen J, Luk JM. miR-122 targets pyruvate kinase $\mathrm{M} 2$ and affects metabolism of hepatocellular carcinoma. PloS one. 2014;9(1):e86872.

45. Krutzfeldt J, Rajewsky N, Braich R, Rajeev KG, Tuschl T, Manoharan M, Stoffel M. Silencing of microRNAs in vivo with 'antagomirs'. Nature. 2005;438(7068):685-9.

46. Gong J, He XX, Tian A. Emerging role of microRNA in hepatocellular carcinoma (review). Oncol Lett. 2015;9(3):1027-33.

47. Nakao K, Miyaaki H, Ichikawa T. Antitumor function of microRNA-122 against hepatocellular carcinoma. J Gastroenterol. 2014;49(4):589-93.

48. Tsai WC, Hsu PW, Lai TC, Chau GY, Lin CW, Chen CM, Lin CD, Liao YL, Wang $J \mathrm{~L}$, Chau YP, et al. MicroRNA-122, a tumor suppressor microRNA that regulates intrahepatic metastasis of hepatocellular carcinoma. Hepatology. 2009:49(5):1571-82.

49. Fonsato V, Collino F, Herrera MB, Cavallari C, Deregibus MC, Cisterna B, Bruno S, Romagnoli R, Salizzoni M, Tetta C, et al. Human liver stem cellderived microvesicles inhibit hepatoma growth in SCID mice by delivering antitumor microRNAs. Stem Cells. 2012;30(9):1985-98.

50. Tu T, Budzinska MA, Maczurek AE, Cheng R, Di Bartolomeo A, Warner FJ, McCaughan GW, McLennan SV, Shackel NA. Novel aspects of the liver microenvironment in hepatocellular carcinoma pathogenesis and development. Int J Mol Sci. 2014;15(6):9422-58.

51. Li C, Deng M, Hu J, Li X, Chen L, Ju Y, Hao J, Meng S. Chronic inflammation contributes to the development of hepatocellular carcinoma by decreasing miR-122 levels. Oncotarget. 2016;7(13):17021-34.

52. Nakamura M, Kanda T, Sasaki R, Haga Y, Jiang X, Wu S, Nakamoto $S$, Yokosuka O. MicroRNA-122 inhibits the production of inflammatory cytokines by targeting the PKR activator PACT in human hepatic stellate cells. PLoS One. 2015;10(12):e0144295.

\section{Publisher's Note}

Springer Nature remains neutral with regard to jurisdictional claims in published maps and institutional affiliations.

Ready to submit your research? Choose BMC and benefit from:
- fast, convenient online submission
- thorough peer review by experienced researchers in your field
- rapid publication on acceptance
- support for research data, including large and complex data types
- gold Open Access which fosters wider collaboration and increased citations
- maximum visibility for your research: over 100M website views per year
At BMC, research is always in progress.
Learn more biomedcentral.com/submissions

